\title{
Rainfall-Runoff of Anthropogenic Waste Indicators from Agricultural Fields Applied with Municipal
}

\section{Biosolids}

JAMES L. GRAY*, ${ }^{*}$ THOMAS BORCH,${ }^{\text {b,c }}$

EDWARD T. FURLONG, ${ }^{\mathrm{a}} \mathrm{JESSICA} \mathrm{G.} \mathrm{DAVIS},{ }^{\mathrm{b}}$ TRACY J. YAGER, ${ }^{\mathrm{d}}$ YUN-YA YANG, ${ }^{\mathrm{b}}$ AND DANA W. KOLPIN $^{\mathrm{e}}$

${ }^{a}$ National Water Quality Laboratory, U.S. Geological Survey, Denver Federal Center, Denver, Colorado 80225-0046.

${ }^{\mathrm{b}}$ Department of Soil and Crop Sciences, Colorado State University, Fort Collins, Colorado 80523-1170.

${ }^{c}$ Department of Chemistry, Colorado State University, Fort Collins, Colorado 80523-1872.

${ }^{\mathrm{d}}$ Colorado Water Science Center, U.S. Geological Survey, Denver Federal Center, Denver, CO, 80225.

${ }^{\mathrm{e}}$ Iowa Water Science Center, U.S. Geological Survey, 400 S. Clinton St. Suite 269, Iowa City, IA, 522441230.

*To whom correspondence should be sent:

James L. Gray, U.S. Geological Survey, National Water Quality Laboratory,

Denver Federal Center, Building 95

P.O. Box 25585

Denver, CO, 80225, USA

Phone: +1-303-236-3776, Fax: +1-303-236-3499, email: jlgray@usgs.gov
Abstract
The presence of anthropogenic contaminants such as antimicrobials, flame-retardants, and 
plasticizers in runoff from agricultural fields applied with municipal biosolids may pose a potential threat to the environment. This study assesses the potential for rainfall-induced runoff of 69 anthropogenic waste indicators (AWIs), widely found in household and industrial products, from biosolids amended field plots. The agricultural field containing the test plots was treated with biosolids for the first time immediately prior to this study. AWIs present in soil and biosolids were isolated by continuous liquid-liquid extraction and analyzed by full-scan gas chromatography/mass spectrometry. Results for 18 AWIs were not evaluated due to their presence in field blank QC samples, and another 34 did not have sufficient detection frequency in samples to analyze trends in data. A total of 17 AWIs, including 4-nonylphenol, triclosan, and tris(2butoxyethyl)phosphate), were present in runoff with acceptable data quality and frequency for subsequent interpretation. Runoff samples were collected 5 days prior to and 1, 9, and 35 days after biosolids application. Of the 17 AWIs considered, 14 were not detected in pre-application samples, or their concentrations were much smaller than in the sample collected one day after application. A range of trends was observed for individual AWI concentrations (typically from 0.1 to $10 \mathrm{ug} / \mathrm{L}$ ) over the course of the study, depending on the combination of partitioning and degradation mechanisms affecting each compound most strongly. Overall, these results indicate that rainfall can mobilize anthropogenic contaminants from biosolids-amended agricultural fields, directly to surface waters and redistribute them to terrestrial sites away from the point of application via runoff. For 14 of 17 compounds examined, the potential for runoff remobilization during rainstorms persists even after three 100 -year rainstorm-equivalent simulations and the passage of a month.

\section{Introduction}

The presence of anthropogenic contaminants in the environment has become a growing concern because low part-per-trillion concentrations of these chemicals can cause adverse impacts on aquatic organisms (Vajda et al. 2008, Kolodziej et al. 2004). Possible sources to the environment include discharges from wastewater treatment plants (WWTPs) (Chang et al. 2011, Ying et al. 2009, Pal et al. 2010, Phillips et 
al. 2012, Barber et al 2013), use of reclaimed water for irrigation (Wang et al. 2005, Miller et al. 2016), domestic septic systems (Swartz et al. 2006, Conn et al. 2006), effluents from concentrated animal feeding operations (CAFOs) Chen et al. 2010, Gadd et al. 2010, Mansell et al. 2011), and runoff from agricultural fields where manure and biosolids (organic-rich solids resulting from treatment of sewage sludge) are applied as fertilizers and soil amendments (Jacobsen et al. 2005, Jenkins et al. 2009, Gall et al. 2011, Yang et al. 2012). Most of the existing research on runoff from manure or biosolids-amended fields has focused on steroid hormones, pharmaceuticals, or antibiotics, as these classes include compounds that are known to be biologically active at very low levels. A study by our research group documented steroid runoff from a field amended with biosolids during a simulated 100-year rainfall event (Yang et al. 2012). This report expands upon on that study and presents data from samples collected contemporaneously with the steroids for a suite of 69 anthropogenic waste indicators (AWIs) in simulated rainfall runoff.

Biosolids typically contain a much broader set of organic contaminants than manure does, as many chemicals for both domestic and industrial use are disposed of via sanitary sewers and ultimately treated in WWTPs. Although removal from the aqueous phase is often substantial for AWIs, such removal is accounted for by a combination of chemical transformations and physical partitioning processes. The fraction of AWI load that is not transformed or remineralized chemically or biologically remains sorbed to biosolids when spread on agricultural land as fertilizer (Furlong et al. 2010, Phillips et al. 2012, Yang and Metcalfe, 2006, Heidler and Halden, 2008 ).

Numerous laboratory studies have investigated the persistence and degradation pathways of AWIs in manure, WWTP-affected streams and groundwater, and biosolids. However, most studies conducted to explore AWI behavior in agricultural settings have been conducted under laboratory, rather than field, conditions and have addressed antibiotics and hormones, which typically are much more prevalent in manure than AWIs derived from household and industrial uses. A recent review article evaluated the behavior of many persistent organic pollutants (POPs) and a handful of pharmaceuticals in biosolidsamended agricultural soil (Clarke and Cummins, 2015), but included only two of the domestic and 
industrial-use AWIs examined herein. Hormones, antibiotics and other pharmaceuticals, and POPs have deservedly received attention because of their strong biological activity and demonstrated effects on aquatic organisms. However, AWIs such as alkylphenol ethoxylates (APEOs) are known endocrine-disrupting chemicals (Jobling and Sumpter, 1993) that may be present in WWTP effluent and biosolids at concentrations that are orders of magnitude higher, making the compounds of comparatively low potency potentially environmentally relevant. Available evidence shows that while there is some potential for transformation of hormones, antibiotics, and other ECs in situ after biosolids or manure have been applied to agricultural lands, they likely persist long enough to impact the quality of runoff water (Jacobsen et al. 2005, Stumpe and Marschner 2007, Yang et al. 2012).

In the United States, it is estimated that the average WWTP produces $240 \mathrm{~kg}$ dry weight of solids per million liters of wastewater treated, resulting in approximately 8 million tons of biosolids produced per year, of which about $50 \%$ are land applied (Kinney et al. 2006). Little is known about the potential for runoffinduced transport of these AWIs after land application of biosolids, although experimental work by our group (Yang et al. 2012) and others (Mansell et al. 2011) indicates that biosolid-derived hormones can be present in simulated runoff at substantial, environmentally relevant concentrations (10s to $100 \mathrm{~s}$ of $\mathrm{ng} / \mathrm{L}$ ). Similar effects have been noted in manure-impacted systems, where endocrine disruption of fish native to receiving waters has also been documented (Cavellin et al. 2014).

The data presented here were derived from replicate samples collected during the same rainfall simulations as the samples analyzed for hormones in Yang et al. (2012). Note that in both studies the rainfall simulation replicated a 100-year rainfall event, so contaminant loads probably represent an upper bound for what might be observed in a natural rainstorm. After 35 days and three simulated storms, runoff concentration of hormones had decreased relative to the first rainfall event but remained at comparatively high levels. These data suggest a substantial biosolid-derived hormone reservoir remains present in soil after 35 days and three 100-year rainfall events, even if leaching and (possibly) in situ transformation occurred. Thus, the main objectives of this study were to evaluate the potential for AWI runoff from 
agricultural test plots treated with biosolids, to elucidate the major transport mechanisms, and to compare the results to available literature on the runoff of hormones and other more intensively studied compounds.

\section{Experimental Section}

\subsection{Experimental Site and Sample Collection}

The field site for this study was located in agricultural eastern Colorado (latitude $40^{\circ} 06^{\prime} 08^{\prime}$ 'N, longitude $104^{\circ} 12^{\prime} 43^{\prime} \mathrm{W}$ ) and was used to grow winter wheat. The site had not previously been treated with biosolids. Briefly, five similar experimental plots were laid out; soil samples were taken prior to any biosolids application or rainfall simulation took place in order to determine if any of the targeted compounds were present in the soil as background prior to biosolids application. Rainfall simulations were conducted 5 days prior to biosolids application (agronomic rates), and 1, 8, and 35 days after application. On two of the plots, rainfall simulations were not conducted until 35 days after application to evaluate the fate of compounds over that time period in the absence of repeated rainfall. Extensive details on site conditions, sampling protocols, biosolids source and application rate, and other field procedures are available in Yang et al. (2012). After each simulated rainfall event, 1-L samples were immediately stored on ice and transported back to the laboratory where they were stored at $4^{\circ} \mathrm{C}$ until extraction and analysis within 14 days. A composite sample was collected from several points within the pile containing biosolids applied to the field at the time of application. This composite sample was analyzed for 57 of the 69 compounds determined in the water analyses.

Results from experimental samples were compared to the field blank QC samples collected from the nozzle of the rainfall simulator to ensure that the water had been exposed to all possible sources of contamination from the tank through the flow channels of the rainfall simulator. If the concentration of a given compound in a runoff sample was less than 3 times the average QC sample, that result was censored. If the runoff concentration fell between 3 and 10 times the average QC concentration, the result was flagged as having 
potential bias due to background contamination. If the runoff concentration was greater than 10 times the QC concentration, the result was considered valid without qualification. After a censor/qualify decision was made on the individual compounds, the entire data set was evaluated, and compounds with sufficient blank interference to prevent trend analysis through the course of the study were omitted from further analysis or interpretation. The raw data for all compounds analyzed, including those omitted from this analysis, are publicly available through the USGS National Water Information System (NWISSample

\section{Analysis).}

Sixty-nine AWIs, including flame retardants, plasticizers, synthetic musks, antibacterials, and surfactant degradates, were isolated by continuous liquid-liquid extraction and quantified by capillary GC/MS operated in full-scan acquisition mode. A detailed description of the sample preparation and instrumental analysis procedures along with performance data collected during method evaluation can be found in Zaugg et al. (2006). Throughout this study, when GC retention time, EI-MS ion ratios, and peak signal-to-noise ratio meet qualitative criteria, results are reported below the MRL, which is statistically derived. When no qualitative identification can be made, the result is reported as " $<$ MRL" Eighteen AWIs were eliminated from analysis due to blank contamination issues described in the previous section.

Fifty-seven AWIs were determined in biosolids samples using pressurized-liquid extraction to extract the compounds followed by sequential OASIS HLB and by Florisil SPE cartridge clean up to isolate and concentrate AWIs from the co-extracted organic matrix and capillary-column GC/MS in full-scan mode was used for quantification (Burkhardt et al., 2005, 2006). No field blank QC was analyzed, but burned Ottowa sand was used as a blank matrix for laboratory QC. Due to differences in sample processing, many of the systematic biases affecting the analysis of water samples were not encountered. Nevertheless, many of the AWIs analyzed in this study are high-use chemicals that can be the source of low-level blank contamination, so any compound censored in runoff sample results was not reported in solids either. 15 of the 17 compounds selected for further analysis in water samples were detected in the biosolids sample, and the two that weren't may have been present below their detection limit. This is not an unusual occurrence as the 
water method is typically more sensitive than the solids method for AWIs owing to the fact that 1-L of water is extracted and analyzed compared to $0.1-1 \mathrm{~g}$ of solid material. A detailed description of method procedures and performance metrics for solids analysis can be found in Burkhardt et al. 2006.

\subsection{Quality Assurance/Quality Control}

Throughout the study, regular verification of method performance was conducted by using spikerecovery experiments and analysis of blank samples. At least one spike and one blank were analyzed per set of 10 samples, for a total of 5 each during the course of the study. For all target compounds, spike recovery averaged $89.9 \pm 9.4 \%$, ranging from $76.3 \pm 20.3 \%$ for coprostanol to $103 \pm 16.3 \%$ for tributyl phosphate (TBP). There were sporadic detections of the 17 targeted AWIs in laboratory blanks, but none exceeded the relevant MRL or approached the concentrations observed in runoff samples. In addition to routine laboratory QC, different types of field blanks were collected prior to sampling on three of four sampling dates. These QC samples were used to assess whether blank limitations precluded runoff trend analysis for a given compound. No field blanks were collected during the final sampling event, 35 days after biosolids application. A total of 12 field blanks were collected over the course of the study. Five of these blanks consisted of organic-free blank water poured through the runoff collection trough to evaluate the trough as a potential source of contamination. Six blanks were local groundwater pumped through the entire rainfall simulator. Between these two different types of blank, every part of the apparatus that could be a source of contamination was tested. Finally, one sample of the groundwater was collected without putting it in the storage tank or running it through the simulator to assess if there was background of any compounds derived from the water source.

Out of 43 compounds detected at least once in a runoff sample, 5 had severe chronic blank contamination (defined as detections that were of comparable magnitude to detections in field samples in $25 \%$ or more of the blanks). Three of these (bisphenol A and two phthalates) most likely leached into the water from the plastic tank used to pump the water to the field plots. Also, metolachlor is an herbicide that may have been applied to the area in the past, as the field had previously been in agricultural use, but 
without biosolids application. Lastly, phenol was ubiquitously present in field and laboratory blanks. These compounds were excluded from further analysis. An additional 17 compounds had moderate chronic blank contamination (defined as that were of comparable magnitude to detections in field samples in fewer than $25 \%$ or more of the blanks). Of these, only cholesterol and triphenyl phosphate (TPP) were detected frequently enough in samples to warrant trend analysis. They were included in the study while the others were excluded on the basis of low detection frequency.

To determine whether a particular compound with moderate blank contamination was included in the analysis, a standardized methodology used by USGS to assess blank contamination was used (U.S. Geological Survey, 2012). This methodology is typically applied to laboratory blank results, but in this case results from field blank samples were used instead. This allows for the consideration of background contamination resulting from both field collection and laboratory processing. If the concentration in environmental samples was less than three times the mean blank concentration, the result for that sample was censored and if the result was between three and ten times the mean blank concentration, that result was flagged with a "V" to indicate possible bias and given additional scrutiny. The remaining 15 compounds had low and/or infrequent blank detections, and data are reported without qualification.

In all, 18 of the 69 AWIs that were measured in this study were excluded from further analysis due to excessive concentration in field blanks. The AWIs analyzed for this method were selected because of their high usage levels, and many have commonly been observed in both laboratory and field blank samples when this GC/MS method has been applied to other USGS field studies over 9 years both prior (June 2006 to April 2008) and subsequent to the analysis of these runoff samples. Of the remaining 51 AWIs, 17 were never detected in either a field blank or a runoff sample and another 17 were detected in less than $2 / 3$ of the runoff samples collected one day after the first rainfall simulation. This leaves a data set of 17 compounds suitable for further analysis to determine their behavior during rainfall simulations.

Finally, each sample or blank had four surrogate compounds (bisphenol A- $d_{3}$, caffeine ${ }^{13} C_{3}$, decafluorobiphenyl, and fluoranthene- $d_{10}$ ) added prior to laboratory analysis to assess analytical recovery 
through extraction and analysis. Surrogate recovery for runoff samples $(n=33)$ ranged from $51.2 \pm 10.8 \%$ to $74.9 \pm 7.5 \%$. These recoveries are in line with typical performance for this method.

\section{Results \& Discussion}

\subsection{AWI Runoff during a Series of Rainfall Events}

Fifteen of the 17 compounds selected for detailed analysis were detected in the biosolids samples, representing a wide range of concentrations (Table 1). In the rainfall simulation 5 days prior to biosolids application, 19 compounds were detected in at least one runoff sample, most at concentrations at or below method reporting limits (MRLs).

Three compounds were present in at least one pre-simulation sample at a concentration substantially higher than their MRL: two natural sterols that commonly occur in all plants (cholesterol and beta-sitosterol), and a flame retardant (tris(2-butoxyethyl)phosphate [TBEP]). It is not surprising that plant sterols may have been present in the soil prior to biosolids application.

In comparison, substantial concentrations of AWIs were observed in samples of simulated runoff produced one day after biosolids application. Thirty-one AWIs were observed in runoff with 17 present in at least 6 of the 9 samples collected. These 17 compounds were the ones selected for further investigation (Figure 1). During each rainfall simulation, a sample was collected at the beginning, middle, and end of the experiment, and rainfall simulations were conducted on three plots. Sampling times were determined in the same way as described previously (Davis et al., 2006). Of the 17 AWIs, 14 had a mean concentration on day 1 at least three times greater than the mean concentration from the pre-application experiment, suggesting that their presence in runoff resulted directly from applied biosolids and not from their presence in the field prior to biosolids addition. Cholesterol, beta-sitosterol, and triphenyl phosphate are all observed in runoff in substantial concentrations both before and after biosolids were applied. Concentrations of all three increase slightly in day 1 runoff compared to pre-biosolids application runoff, but 
the increases are not statistically significant.

Runoff samples collected one day after biosolids application contained significantly $(p<0.05)$ higher concentrations of the other 14 of 17 AWIs than pre-application samples (Figure 1). Overall, the mean AWI concentration on day 1 ranged from $0.057 \mu \mathrm{g} / \mathrm{L}$ (acetylhexamethyl tetrahydronaphthalene [AHTN]) to 6.0 $\mu \mathrm{g} / \mathrm{L}$ (4-nonylphenol [4-NP]).

Concentrations ( $\mu \mathrm{g} / \mathrm{L}$; averaged across plots) for each rainfall event are shown for different sampling days (Figure 1), and generally decreased or remained constant for most compounds from day 1 to day 35. Because these compounds do not seem to be depleted in the soil over time, it is likely that they are somewhat resistant to microbial degradation and the extent of leaching into the dissolved phase is small. This is not surprising given the nature of biosolids. They are the end product of an extensive sequence of both aerobic and anaerobic biological treatment processes. Any compound that is susceptible to microbial processes is likely to be degraded in a WWTP prior to biosolids application, and therefore less likely to be present in the land-applied biosolids. Indeed, when a mass balance was constructed at several large metropolitan WWTPs, many of the same AWIs not observed in these samples were degraded very efficiently. Furlong et al. (2010, 2011) calculated instantaneous loads of these compounds for both solid and liquid waste streams, and showed that total mass flux out of the plant was reduced by over $95 \%$ in some cases relative to WWTP influent. This is an important distinction, as many investigations of WWTP processes that demonstrate removal of trace organic compounds focus on the aqueous fraction of the total waste stream and neglect the biosolids-associated fraction (Heidler and Halden, 2008). Contaminant removal from the aqueous phase is demonstrably beneficial for mitigating effects related to direct discharge of treated wastewater to aquatic ecosystems. However, compounds that are resistant to microbial degradation and have an affinity for hydrophobic particles will persist in biosolids, and land application of biosolids as fertilizer provides an indirect source of these contaminants to surface waters.

The fact that some AWIs do not decrease in concentration in runoff after several rainfall simulations also suggests that the total mass of AWIs in the biosolids/soil mixture was not greatly depleted over the 
course of these experiments (Figure 1A, 1B). There are several possible explanations for this. The total mass of AWIs that leached from the soil after biosolids application could be small relative to the mass of AWIs in the biosolids themselves, leaving a large reservoir for subsequent leaching. Also, the release of AWIs during leaching from the soil/biosolids mixture could be minimal. A third possibility is that biosolids particulates are being washed down by the runoff, and the AWIs remain associated with the suspended solids rather than being leached into the dissolved phase. The AWIs were isolated by continuous liquid-liquid extraction of unfiltered runoff samples into dichloromethane (DCM) from water. Because there is no filtration step, any particle-bound AWIs are subjected to the same extraction conditions as those that are dissolved. Two (additional) test plots were subjected to simulated rainfall for the first time 35 days after biosolids were applied, and AWI concentrations in the runoff from those simulations (Figure 2) were compared to concentrations in the runoff 1 day after application for the 3 test plots shown in Figure 1 . For most compounds, in situ attenuation appears minimal as runoff concentrations were comparable (Figure 2B) or even greater (Figure 2A) after 35 days. This suggests that natural weathering processes may make some compounds more easily leachable from the biosolids/soil mixture even in the absence of precipitation.

In contrast, concentrations of several other AWIs in runoff did trend downward over the course of the experiment (Figure 1C). These compounds apparently are being depleted in the soil/biosolids mixture, and less mass is available for transport after each subsequent rainfall simulation. Leaching into runoff is the most likely mechanism of AWI source depletion that would be associated with rainfall events. However, indole, menthol, and skatole are reduced by $80 \%$ or more in runoff when the first rainfall simulation occurs 35 days after biosolids application compared to 1 day afterwards (Figure 2C). Clearly, some in situ attenuation is occurring without leaching and runoff. This phenomenon is observed to a lesser extent for TBP (Figure 2B), and the most likely in situ removal mechanisms are microbial degradation or volatilization. In contrast, p-cresol is not substantially attenuated in situ when no rain simulations occurred for 35 days, but in the plots where rainfall simulations were conducted one and eight days after biosolids application, little remains on day 35. This suggests that $\mathrm{p}$-cresol is being leached, not just transported in association with 
particulate matter.

The AWIs depicted in Figures 1A and 1B do not appear to be less available to runoff after multiple simulations of severe rainfall events, so the entrainment of particulate matter in runoff flow does not affect the concentration of AWIs in the runoff. This makes sense because in the absence of AWI depletion via leaching into the dissolved phase or chemical transformation (by biological or other means), the biosolids that remain on the field have the same mass of AWIs sorbed to them as when they were originally applied. Since neither repeated exposures to 100 -year rainfall equivalent storms nor 35-day exposure to sun, natural rainfall, and soil microbes resulted in significant concentration decline, it appears unlikely that either microbial degradation or leaching from biosolids is particularly effective for reducing concentrations of these AWIs. In cases where runoff concentrations are actually higher after 35 days, weathering of the soil/biosolids matrix likely makes AWIs more easily leachable and thus prone to runoff.

Tributyl phosphate and 4-tert-octylphenol show slightly decreasing concentrations in runoff with each subsequent rainfall event, decreasing in average concentration from $0.30 \pm 0.17$ and $0.49 \pm 0.15$, respectively, on the first day post-application to $0.17 \pm 0.04$ and $0.32 \pm 0.09$ on day 35 . Although decreasing, they are still present in the soil and available for mobilization in future runoff events. Four AWIs were nearly completely depleted in the soil over the course of these experiments. Concentrations of indole decreased over $90 \%$ from $0.32 \pm 0.35$ on day 1 to $0.033 \pm 0.009$ on day 35 , while three additional AWIs that were detected on day 1 are undetectable $(<0.2 \mu \mathrm{g} / \mathrm{L})$ by day 35 . Menthol $(0.34 \pm 0.15$, day 1$)$, 3-methyl1H-indole $(0.078 \pm 0.031)$, and p-cresol $(0.051 \pm 0.77)$ all have substantially lower concentration on day 9 than day 1 , and are not detected on day 35.

The AWIs examined in this study can be categorized into several groups. All of the AWIs discussed herein were detected in runoff samples, often at relatively high concentrations. This is likely due to physical sorption to biosolids that become suspended particles in the runoff stream. Particle wetting and suspension does not appear to deplete the AWI load in the soil sufficiently to decrease the runoff concentration in subsequent rain simulations. The differences between the categories enumerated below lie in the potential 
processes that likely contribute to lower concentration in subsequent rainfall simulations.

The categories are: 1) AWIs that are detected in runoff, often at relatively high concentrations, but the biosolids associated concentration is not depleted to the point that runoff concentrations decrease for subsequent rainfall events. It seems likely that these compounds remain particle bound in the runoff, and do not degrade in soil or leach into runoff at an appreciable rate, 2) AWIs that decrease in concentration with each subsequent runoff event but are persistent in the soil/biosolids matrix in the absence of exposure to rainfall. Some fraction of these compounds may remain particle bound, but some other mechanism is also influencing their persistence, and is associated with rainfall, be it leaching into runoff or enhanced microbial activity in saturated soil, 3) AWIs where similar runoff concentration decreases occur whether or not the plot is exposed to repeated rainstorms. In these cases, an in situ loss process such as photodegradation, volatilization or microbial degradation are likely responsible for the decrease in concentration. These categories reflect an interesting contrast to the results from our previously published paper (Yang et al. 2012). The samples used in these studies were replicates collected in the field at the same time. All field conditions were identical; the only difference is that one replicate was analyzed for steroid hormones and the other for AWIs. Hormones are biogenic molecules that share a common structural skeleton, and it is well known that they can interconvert through microbial activity in the environment. If hormone concentrations increase after multiple rainfall simulations and exposure to environmental soil conditions, it is possible that the observed increases result from degradation of a closely related compound. Almost all of the AWIs are synthetic compounds produced for human use, although some (e.g. nonylphenol) are degradates of related synthetic AWIs and some (e.g., cholesterol) occur in nature. It is highly unlikely that a synthetic chemical will be formed through microbial activity in the environment, but that process is common for biogenic compounds where microbial communities have had millions of years instead of dozens to adapt to their presence in the environment.

\subsection{AWI Load to Receiving Waters}


Up to this point, the discussion has primarily focused on AWI concentrations in simulated rainfall runoff. This is informative both because the rainfall simulations on adjacent field plots provide a source of pseudo-replicated data where such direct comparisons are useful, and because any organism exposed to biologically active chemicals responds to the concentration of that chemical through its mechanism of exposure (water, soil, dietary exposure, etc.). However, it is also informative to consider where that exposure may be taking place. While there are doubtless some organisms exposed to biosolids-derived contaminants at the point of application, it is more likely for any exposure to occur downstream in receiving waters where AWI inputs may be diluted by flow from unimpacted sources upstream. For that reason it is important to also consider the total load of AWIs being discharged to the environment where:

$$
\text { AWI Load }(\mu \mathrm{g} / \mathrm{min})=[\mathrm{AWI}](\mu \mathrm{g} / \mathrm{L}) \times \text { Runoff Flow Rate }(\mathrm{L} / \mathrm{min})
$$

The rainfall simulations conducted 5 days before biosolids application were conducted on plots nearby those used after application, so the test plots were not exposed to simulated rain prior to the first experiments one day after biosolids application. This is evident in the data for both runoff flow and AWI load (Figure 3). All of the subplots of figure 3 use the same scale for load, flow, and time of simulation to facilitate easy visual comparison. On day 1 , all three test plots have an initial flow rate of less than $0.05 \mathrm{~L} / \mathrm{min}$, which increases gradually over the course of about an hour to approximately $1 \mathrm{~L} / \mathrm{min}$ or less. This is because most of the initial rainfall is absorbed by the relatively dry soil and it takes some time for the soil to become saturated. On day 8, flow rate increases much more quickly and peaks above $3 \mathrm{~L} / \mathrm{min}$ after 25-35 minutes. The conditions on day 35 are intermediate between day 1 and day 9; rainfall simulations have been conducted on the plots, but the soil has had 26 days to dry out instead of 8 days. Flow initially increases slowly, but eventually rises to approximately $2 \mathrm{~L} / \mathrm{min}$ after $40-50$ minutes.

Although in most cases the concentrations of AWIs were comparable or even decreased on each plot with each subsequent rainfall simulation, the AWI load transported off the plot is markedly different. Since load is the product of concentration and flow rate, comparable runoff concentrations result in the potential discharge of a much greater AWI mass to receiving waters in later rainfall simulations. It is worth 
mentioning again that the simulations were the equivalent of an approximately 100 -year rainfall event, but the general conclusion that AWI mass transport is substantially increased during rainstorms that occur when soil is close to saturation should be sound.

On day one, the mass load and flow rate take nearly an hour to stabilize, and the load discharged never exceeds $20 \mu \mathrm{g} / \mathrm{min}$ on any of the plots. On day 8 flow and consequently load increase much more quickly, peaking after 20-30 minutes at nearly $80 \mu \mathrm{g} / \mathrm{min}$ (sum of all $17 \mathrm{AWIs}$ ) for plot 1 and $40 \mu \mathrm{g} / \mathrm{min}$ on plot 3. After the last AWI samples were collected, flow (and presumably load) remain high for an extended period. As with flow rate, the trends in load on day 35 fall somewhere in between the observations on day 1 and day 8. The mass load of AWIs in the runoff increases faster and reaches a higher level than on day 1, but is somewhat diminished when compared to day 8 . This is most likely because the soil is initially drier on day 35 than it was on day 8 . The general implication of these results is that in an arid setting like eastern Colorado, a series of rain events has the potential to mobilize more biosolids-derived organic contaminants than one would observe if storms were less frequent.

\section{Conclusions and Environmental Implications}

We assessed the runoff potential for AWIs from agricultural test plots receiving a first-time application of biosolids. It should be noted that the data herein likely represent a worst-case scenario (100year rainfall event or $65 \mathrm{~mm} \mathrm{~h}^{-1}$ ) for runoff conditions at our field site. That being said, since the completion of this fieldwork, parts of Colorado have experienced two 100-year flood events within a span of 20 months (September 2013, which was a 500-year event, and May 2015). While the occurrence of two 100-year flood events within such a short period of time may be anomalous, it also may reflect shifting regional and global precipitation patterns, and such intense flood events may become more common in Colorado. Furthermore, historical weather patterns in Colorado typically include a late-spring to early summer monsoon season, where the heavier rain storms do tend to be bunched together in time. While 
AWIs were demonstrably present in whole-water runoff from biosolids-amended fields, further transport from immediately off-field to surface waters, wetlands, or elsewhere on the landscape, requires additional study. If runoff-associated AWIs were to reach receiving waters, concentrations likely would be diluted and potential for impact on aquatic organisms would thus likely be lower than for the observed runoff concentrations. Nevertheless, our findings demonstrate that AWIs can be present in runoff from biosolidsamended agricultural fields, and that loading to surface water via runoff may be comparable to that resulting from rainfall immediately after biosolids application even after multiple heavy rainfall events have occurred and over one month has passed.

\section{Acknowledgments}

This research was supported by the Colorado Water Institute (CWI) and a National Science Foundation (NSF) CAREER Award (EAR 0847683) to T. B. Support also was provided by the USGS Toxic Substances Hydrology Program's Emerging Contaminant Project. The authors thank William Foreman (USGS), Corey Stephens (USGS), Jeff Writer (USGS), Adriane Elliott (CSU), and Kathy Doesken (CSU) for their invaluable technical assistance. The authors also thank Mr. Doug Lingo for the access to his farm. Any use of trade, firm, or product names in the paper is for descriptive purposes only and does not imply endorsement by the U.S. Government. 


\section{FIGURE CAPTIONS}

FIGURE 1. Boxplot showing runoff concentration distribution of detected anthropogenic waste indicators in runoff samples collected from three plots during simulated rainfall 5 days prior to biosolids application (-5) and 1, 8, and 35 (no measurements were made from plot 2 on day 8 or plot 3 on day 35) days afterwards. Boxes indicate $25^{\text {th }}$ and $75^{\text {th }}$ percentile values and whiskers are drawn to the highest and lowest data points that are not outliers. The dashed lines indicate method detection limit.

FIGURE 2: Boxplot showing runoff concentration distribution of detected anthropogenic waste indicators in runoff samples collected from two plots (different from the plots shown in Figure 1) during simulated rainfall 5 days prior to biosolids application (-5) and 1 and 35 days after. All data are from plots subjected to simulated rainfall for the first time on the date sampled. The dashed lines indicate method detection limit.

FIGURE 3. Hormone mass load and runoff rate (blue circles on secondary axis) from all three plots 1 day, 8 days, and 35 days after biosolids application. No measurements were made for plot 2 on day 8 or plot 3 on day 35 
FIGURE 1:
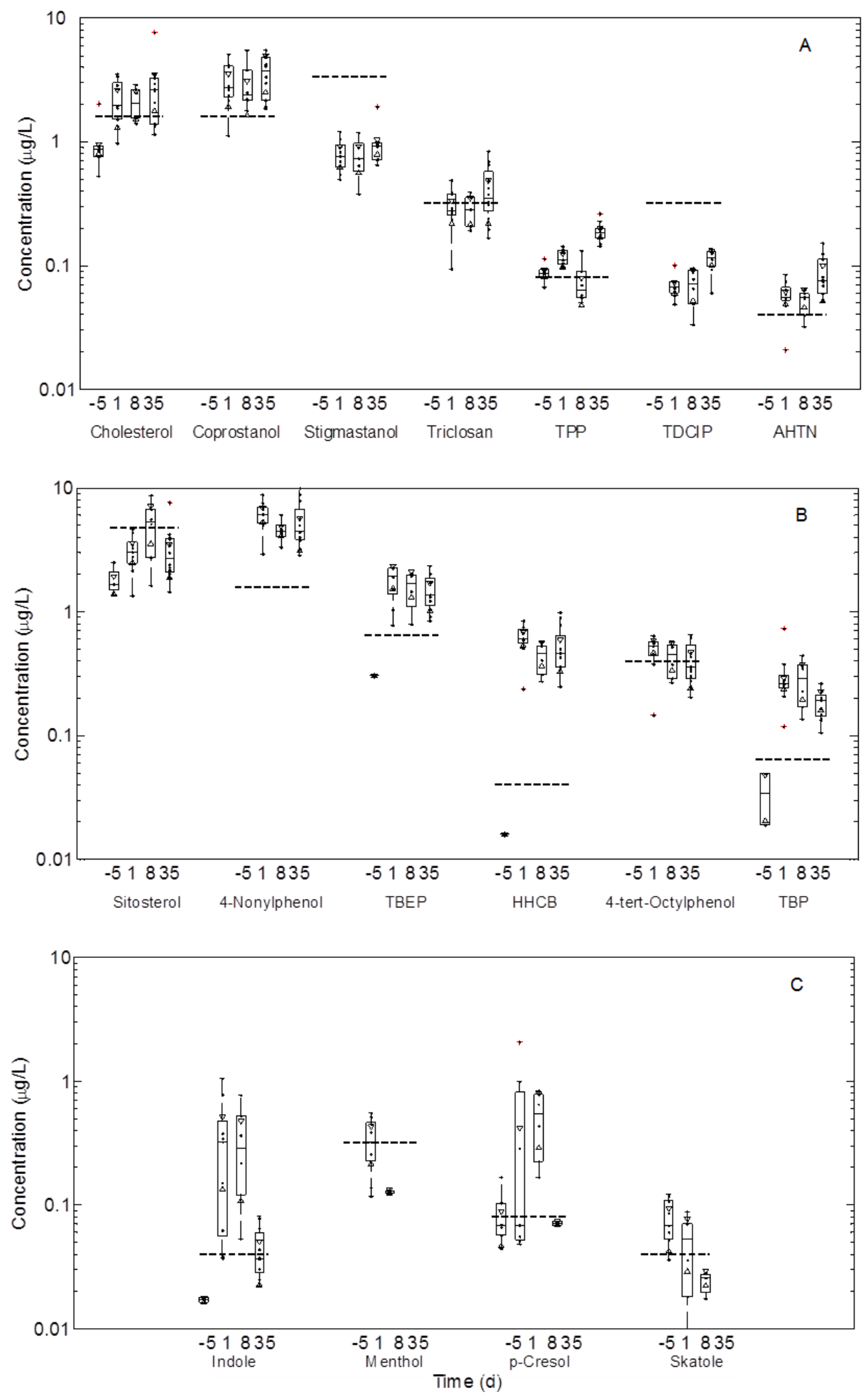
FIGURE 2.
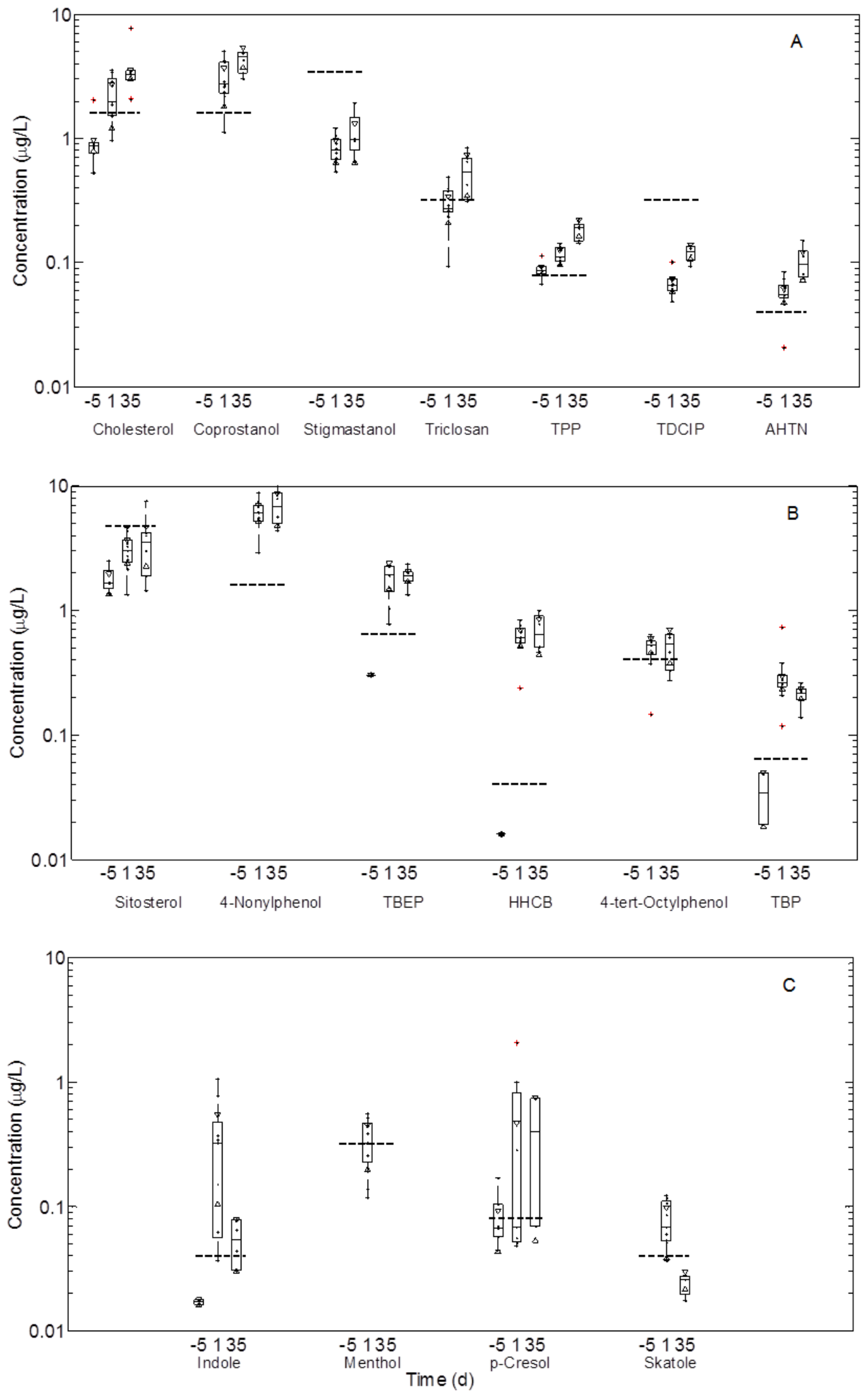
FIGURE 3. Figure 3 is included as a separate file. 
Table 1: List of 17 compounds selected for trend analysis in simulated rainfall runoff samples with any abbreviation used in the text and figures, Chemical Abstract Services Registry Number (CASRN), and measured concentration in biosolids collected prior to field application.

\begin{tabular}{|c|c|c|c|}
\hline Compound & Abbreviation & CASRN & $\begin{array}{c}\text { [Biosolids] } \\
\quad(\square g / L)\end{array}$ \\
\hline Tris(dichloroisopropyl)phosphate & TDCIP & $13674-87-8$ & $\mathrm{E} 209^{\mathrm{a}}$ \\
\hline Triphenyl phosphate & TPP & $115-86-6$ & $\mathrm{E} 22.5^{\mathrm{a}}$ \\
\hline Triclosan & & $3380-34-5$ & 9140 \\
\hline Tributyl phosphate & TBP & $126-73-8$ & $<100$ \\
\hline Tris(2-butoxyethyl)phosphate & TBEP & $78-51-3$ & $\mathrm{E} 312^{\mathrm{a}}$ \\
\hline Menthol & & $89-78-1$ & $<458^{\mathrm{b}}$ \\
\hline Indole & & $120-72-9$ & 9510 \\
\hline Tonalide & HHCB & $1222-05-5$ & 191000 \\
\hline Cholesterol & & $57-88-5$ & $\mathrm{E} 111000^{\mathrm{a}}$ \\
\hline beta-Stigmastanol & Stigmastanol & $19466-47-8$ & $\mathrm{E} 23000^{\mathrm{a}}$ \\
\hline beta-Sitosterol & Sitosterol & $83-46-5$ & $\mathrm{E} 222000^{\mathrm{a}}$ \\
\hline Galaxolide & AHTN & $21145-77-7$ & 3350 \\
\hline 4-tert-octylphenol & 4-t-OP & $140-66-9$ & 6920 \\
\hline 4-Nonylphenol (total) & 4-NP & $140-40-5$ & 325000 \\
\hline 3-methyl-1H-Indole & Skatole & $83-34-1$ & 372 \\
\hline 3-beta-Coprostanol & Coprostanol & $360-68-9$ & $\mathrm{E} 719000^{\mathrm{a}}$ \\
\hline p-Cresol & & $106-44-5$ & 620 \\
\hline
\end{tabular}

${ }^{\mathrm{a}} \mathrm{E}$ indicates that data are reported as estimated. This is commonly due to interference in the chromatogram or the reported value falling outside the calibration limits.

${ }^{b}$ Reporting limit was raised because ion ratio criteria for the compound were not met. 


\section{REFERENCES}

Barber, L.B., Keefe, S.H., Brown, G.K., Furlong, E.T., Gray, J.L., Kolpin, D.W., Meyer, M.T., Sandstrom, M.W. and Zaugg. S.D. Persistence and Potential Effects of Complex Organic Contaminant Mixtures in Wastewater-Impacted Streams. Environ. Sci. Tech. 2013, 47(5), 2177-2188.

Burkhardt, M.R.; ReVello, R.C.; Smith, S.G.; Zaugg, S.D. Pressurized liquid extraction using water/isopropanol coupled with solid-phase extraction cleanup for industrial and anthropogenic waste-indicator compounds in sediment. Anal. Chim. Acta 2005, 534 (1), 89-100.

Burkhardt, M.R., Zaugg, S.D., Smith, S.G., and ReVello, R.C., 2006, Determination of wastewater compounds in sediment and soil by pressurized solvent extraction, solidphase extraction, and capillary-column gas chromatography/mass spectrometry: U.S. Geological Survey Techniques and Methods, book 5, chap. B2, 40 p.

Cavallin, J.E., Durhan, E.J., Evans, N., Jensen, K.M., Kahl, M.D., Kolpin, D.W., Kolodziej, E.P., Foreman, W.T., Lalone, C.A., Makynen, E.A., Seidl, S.M., Thomas, L.M., Villeneuve, D.L., Weberg, M.A., Wilson, V.S., Ankley, G.T. Integrated assessment of runoff from livestock farming operations: Analytical chemistry, in vitro bioassays, and in vivo fish exposures. Environ. Toxicol. Chem. 2014, 33(8), 1849-1857.

Chang, H.; Wan, Y.; Wu, S.; Fan, Z.; Hu, J. Occurrence of androgens and progestogens in wastewater treatment plants and receiving river waters: Comparison to estrogens. Water Res. 2011, 45 (2), 732-740.

Chen, T.S.; Chen, T.C.; Yeh, K.J.C.; Chao, H.R.; Liaw, E.T.; Hsieh, C.Y.; Chen, K.C.; Hsieh, L.T.; Yeh, Y.L. High estrogen concentrations in receiving river discharge from a concentrated livestock feedlot. Sci. Total Environ. 2010, 408 (16), 3223-3230.

Clarke, R.M. and Cummins, E. Evaluation of "Classic" and Emerging Contaminants 
Resulting from the land Application of Biosolids to Agricultural Lands: A Review. Hum. Ecol. Risk Assess. 2015, (21)492-513.

Conn, K.E., Barber, L.B., Brown, G.K., Siegrist, R.L. Occurrence and Fate of Organic Contaminants during Onsite Wastewater Treatment. Environ. Sci. Tech. 2006, 40(23), 7358-7366.

Davis, J.G.; Truman, C.C.; Kim, S.C.; Ascough, J.C.; Carlson, K. Antibiotic transport via runoff and soil loss. J. Environ. Qual. 2006, 35 (6), 2250-2260.

Furlong, E.T., Gray, J.L., Quanrud, D.M., Teske, S.E., Esposito, K., Marine, J., Ela, W.P., Phillips, P.J., Kolpin, D.W., and Stinson, B., 2010, Fate of estrogenic compounds during municipal sludge stabilization and dewatering: Water Environment Research Foundation Final Project Report No. 04-HHE-6, 178 p.

Furlong, E.T.; Gray, J.L.; Quanrud, D.M.; Teske, S.S.; Werner, S.L.; Esposito, K.E.; Marine, J.; Ela, W.P.; Zaugg, S.D.; Phillips, P.J.; Stinson, B. Pharmaceuticals, hormones, anthropogenic waste indicators, and total estrogenicity in liquid and solid samples from municipal sludge stabilization and dewatering. U.S. Geological Survey OpenFile Report 2011.

Gadd, J.B.; Tremblay, L.A.; Northcott, G.L. Steroid estrogens, conjugated estrogens and estrogenic activity in farm dairy shed effluents. Environ. Pollut. 2010, 158 (3), 730736.

Gall, H.E.; Sassman, S.A.; Lee, L.S.; Jafvert, C.T. Hormone discharges from a midwest tiledrained agroecosystem receiving animal wastes. Environ. Sci. Technol. 2011, 45 (20), $8755-8764$.

Heidler, J. and Halden, R.U. Meta-Analysis of Mass Balances Examining Chemical Fate during Wastewater Treatment. Environ. Sci. Tech. 2008, 42(17), 6324-6332.

Jacobsen, A.-M.; Lorenzen, A.; Chapman, R.; Topp, E. Persistence of testosterone and 17 
beta-estradiol in soils receiving swine manure or municipal biosolids. J. Environ. Qual. 2005, 34 (3), 861-871.

Jenkins, M.B.; Endale, D.M.; Schomberg, H.H.; Hartel, P.G.; Cabrera, M.L. 17 beta-Estradiol and testosterone in drainage and runoff from poultry litter applications to tilled and no-till crop land under irrigation. J. Environ. Manage. 2009, 90 (8), 2659-2664.

Jobling, S. and Sumpter, J.P. Detergent components in sewage effluent are weakly oestrogenic to fish: An in vitro study using rainbow trout (Oncorhynchus mykiss) hepatocytes. Aquat. Tox. 1993, 27(3-4), 361-372.

Kinney, C.A.; Furlong, E.T.; Zaugg, S.D.; Burkhardt, M.R.; Werner, S.L.; Cahill, J.D.; Jorgensen, G.R. Survey of organic wastewater contaminants in biosolids destined for land application. Environ. Sci. Technol. 2006, 40 (23), 7207-7215.

Kolodziej, E.P.; Harter, T.; Sedlak, D.L. Dairy wastewater, aquaculture, and spawning fish as sources of steroid hormones in the aquatic environment. Environ. Sci. Technol. 2004, $38(23), 6377-6384$

Mansell, D.S.; Bryson, R.J.; Harter, T.; Webster, J.P.; Kolodziej, E.P.; Sedlak, D.L. Fate of endogenous steroid hormones in steer feedlots under simulated rainfall-induced runoff. Environ. Sci. Technol. 2011, 45 (20), 8811-8818.

Miller, E. L.; Nason, S. L.; Karthikeyan, K. G.; Pedersen, J. A., Root Uptake of Pharmaceuticals and Personal Care Product Ingredients. Environ. Sci. \& Tech. 2016, $50,(2), 525-541$.

Pal, A.; Gin, K.Y.H.; Lin, A.Y.C.; Reinhard, M. Impacts of emerging organic contaminants on freshwater resources: Review of recent occurrences, sources, fate and effects. Sci. Total Environ. 2010, 408 (24), 6062-6069.

Phillips, P.J., Chalmers, A.T., Gray, J.L., Kolpin, D.W., Foreman, W.T., Wall, G.R. Combined Sewer Overflows: An Environmental Source of Hormones and Wastewater 
Micropollutants. Environ. Sci. Tech. 2012, 46(10), 5336-5343.

Stumpe, B.; Marschner, B. Long-term sewage sludge application and wastewater irrigation on the mineralization and sorption of 17 beta-estradiol and testosterone in soils. Sci. Total Environ. 2007, 374 (2-3), 282-291.

Swartz, C.H.; Reddy, S.; Benotti, M.J.; Yin, H.F.; Barber, L.B.; Brownawell, B.J.; Rudel, R.A. Steroid estrogens, nonylphenol ethoxylate metabolites, and other wastewater contaminants in groundwater affected by a residential septic system on Cape Cod, MA. Environ. Sci. Technol. 2006, 40 (16), 4894-4902.

U.S. Geological Survey, 2012, Application of the Result-level 'v' Value Qualifier Code and 'E’ Remark Code to Selected Organic Results Reported by the National Water Quality Laboratory (NWQL): USGS Office of Water Quality Technical Memorandum 2012.01. Accessed June 25, 2015 at: http://water.usgs.gov/admin/memo/QW/qw12.01.pdf

Vajda, A.M.; Barber, L.B.; Gray, J.L.; Lopez, E.M.; Woodling, J.D.; Norris, D.O. Reproductive disruption in fish downstream from an estrogenic wastewater effluent. Environ. Sci. Technol. 2008, 42 (9), 3407-3414.

Wang, Y.Q.; Hu, W.; Cao, Z.H.; Fu, X.Q.; Zhu, T. Occurrence of endocrine-disrupting compounds in reclaimed water from Tianjin, China. Anal. Bioanal. Chem. 2005, 383 (5), 857-863.

Yang, J.-J. and Metcalfe, C.D. Fate of synthetic musks in a domestic wastewater treatment plant and in an agricultural field amended with biosolids. Sci. Total Environ. 2006, $363(1-3), 149-165$.

Yang, Y.-Y.; Gray, J. L.; Furlong, E. T.; Davis, J. G.; ReVello, R. C.; Borch, T., Steroid Hormone Runoff from Agricultural Test Plots Applied with Municipal Biosolids. 
Environ. Sci. Tech. 2012, 46, (5), 2746-2754.

Yang, Y.-Y.; Borch, T.; Young, R.B.; Goodridge, L.D.; Davis, J.G. Degradation kinetics of testosterone by manure-borne bacteria: Influence of temperature, $\mathrm{pH}$, glucose amendments, and dissolved oxygen. J. Environ. Qual. 2010, 39 (4), 1153-1160.

Ying, G.G.; Kookana, R.S.; Kumar, A.; Mortimer, M. Occurrence and implications of estrogens and xenoestrogens in sewage effluents and receiving waters from South East Queensland. Sci. Total Environ. 2009, 407 (18), 5147-5155.

Zaugg, S.D.; Smith, S.G.; Schroeder, M.P., 2006. Determination of wastewater compounds in whole water by continuous liquid-liquid extraction and capillary-column gas chromatography/mass spectrometry: U.S. Geological Survey Techniques and Methods, book 5, chap. B4, 30 p. 


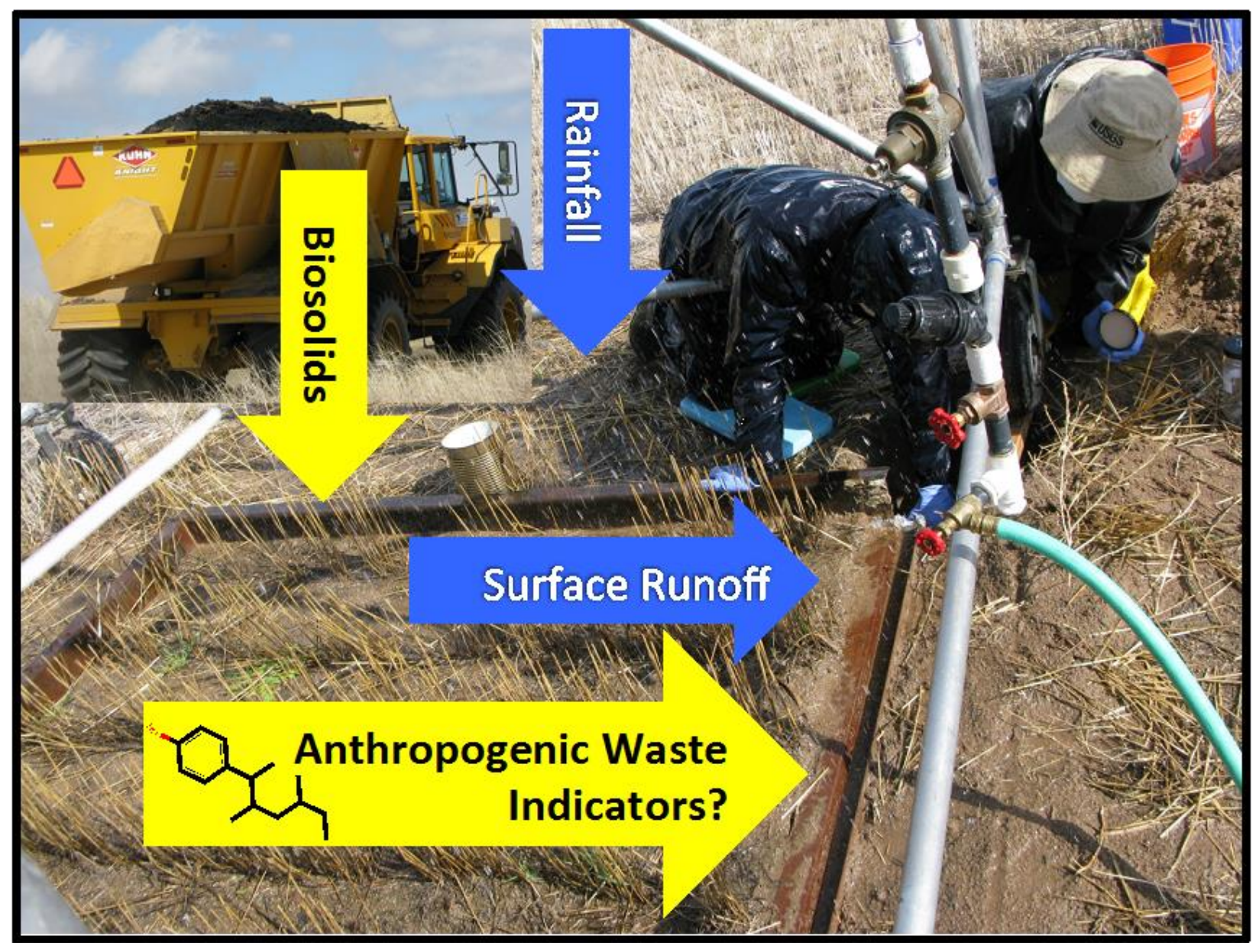

